\title{
Deflection Test of Post-tensioned Unbonded PC Beam
}

\author{
Jun XU \\ School of Civil Engineering \& Architecture \\ Taizhou University \\ Taizhou, China \\ Yingying ZHAO \\ Department of Construction Engineering \\ Henan Polytechnic Institute \\ Nanyang, China \\ Email:332934862@qq.com
}

\author{
Ruige LI*( Corresponding author) \\ School of Civil Engineering \& Architecture \\ Taizhou University \\ Taizhou, China \\ E-mail:lrg_lrg@163.com
}

\author{
Yada XU \\ School of Civil Engineering \& Architecture \\ Taizhou University \\ Taizhou, China \\ E-mail:331429766@qq.com
}

\author{
Chaoqun WENG \\ School of Civil Engineering \& Architecture \\ Taizhou University \\ Taizhou, China \\ E-mail: 895279024@qq.com
}

\begin{abstract}
A PC beam was made and different prestressing force was inflicted to the beam to research the relationship between the prestressing force and the short-term stiffness of the full-PC beam and the partial-PC beam. Under all levels of prestressing force, a concentrated force is exerted at third point. At the same time, the deflection of this beam was collected under different kinds of concentrated load value. Through the calculation and analysis of the calculated deflection value, it is found that the short-term stiffness of the beam increases with the increasing of the prestress, which leads to a certain deviation from the calculation formula of the short-term stiffness of PC beams in which, no cracks, are stipulated in Code for Design of Concrete Structures and Specification for Design of Highway Reinforced Concrete and Prestressed Concrete.In order to calculate the deformation performance of the $\mathrm{PC}$ beams more accurately, the paper suggests that it needs to take the influence of prestressing force into account in the calculation of short -term stiffness.
\end{abstract}

Keywords-prestressed concrete beam; deflection; short-term stiffness; test

\section{INTRODUCTION}

The short-term stiffness of the full-prestressed concrete beam is an important parameter to calculate the deflection of the beam and the dynamic performance of the beam. The second paragraph of article 7.2.3 of Code for Design of Concrete Structures(GB50010-2010)prescribes that[1]: The short-term stiffness $\mathrm{Bs}$ of prestressed concrete flexural member without cracks is equal to $0.85 \mathrm{E}_{\mathrm{c}} \mathrm{I}_{0}$. The second paragraph of article 6.5.2 of Specification for Design of Highway Reinforced Concrete and Prestressed Concrete (JTG D62-2004) prescribes that[2]: The short-term stiffness of flexural member of full-prestressed concrete and prestressed concrete of chass $\mathrm{A}, \mathrm{B}_{0}$, is equal to $0.95 \mathrm{E}_{\mathrm{c}} \mathrm{I}_{0}$. But in fact there are a lot of literatures which indirectly prove that the prestressing force is related to the stiffness of the beam[3,4,5]. The relationship between the short-term stiffness and the prestress of PC beams was researched by making the load -deflection test of PC beams in this paper. The result can provides reference basis for PC beam in its structure design[6], construction[7], maintenance of normal use period, safety monitoring, etc[8,9].

\section{Test Design}

\section{A. Test Component Design}

A non-bonded prestressed concrete beam, made in the laboratory of Structural Laboratory of Taizhou University in March 2016, is used to make a loading experiment, which helps to study the influence of the existing prestress on the short-term stiffness of the concrete beam.In the first place, pull the prestressing tendon and exert prestress of different levels to the beam and simulate the size of the existing prestress in the prestressed beam .Under each level of prestress, load at the third point of the beam and collect the mid span deflection. Analyze the deflection variation of beams at different loads under prestress of different levels. The size of beam section and other parameters are shown in Fig. 1. Among those, the size of the regular reinforcement is 4Ф6, and the type of the reinforcement is HPB300; The size of the prestressed steel strand is $7 \Phi^{\mathrm{S}} 5$, and $f_{\text {ptk }}=1720 \mathrm{MPa}$.

In order to minimize the influence of cracks and other factors on the stiffness of beams, it is required that there is no crack in the beam under the action of prestress, and the buckling failure and compression failure cannot be 
produced.Under the above several conditions, it is easy to determine the size of the tensile stress, and the maximum value of the actual tension cannot be greater than $101 \mathrm{kN}$.It is necessary to use the maximum tensile strength of $90 \mathrm{kN}$ to ensure safety.

Start from prestress of 0 , and pull the tension to the maximal tension of $90 \mathrm{kN}$ by dividing the tension into 5 levels on average .Go on multi-stage loading process after pulling the tension to the scheduled prestress, then collect the deflection value of the beam and pull the tension to the next level after collecting. Actual tensioning levels are shown in Tab. 2.

TABLE I. THE CLASSIFICATION OF NON-BONDED PRESTRESSED TENSIONS

\begin{tabular}{|c|c|c|c|c|}
\hline $\begin{array}{c}\text { Stretching } \\
\text { force } \\
\mathbf{P}(\mathbf{k N})\end{array}$ & $\begin{array}{c}\text { Standard } \\
\text { values of } \\
\text { prestressed } \\
\text { steel } \\
\text { strand } \\
\text { strength } \\
\boldsymbol{f}_{\text {ptk }} \text { (MPa) }\end{array}$ & $\begin{array}{c}\text { Prestressed } \\
\text { steel } \\
\text { strand } \\
\text { area } \\
\boldsymbol{A}_{\mathbf{p}}\left(\mathbf{m m}^{\mathbf{2}}\right)\end{array}$ & $\begin{array}{c}\text { Control stress } \\
\text { for } \\
\text { prestressing } \\
\text { (MPa) }\end{array}$ & $\begin{array}{c}\boldsymbol{\sigma}_{\text {con }} / \boldsymbol{f}_{\text {ptk }} \\
(\boldsymbol{\%})\end{array}$ \\
\hline 0 & 1720 & 139 & 0 & 0 \\
\hline 16.7 & 1720 & 139 & 120.1 & 6.99 \\
\hline 34.9 & 1720 & 139 & 251.1 & 14.60 \\
\hline 52.5 & 1720 & 139 & 377.7 & 21.96 \\
\hline 69.0 & 1720 & 139 & 496.4 & 28.86 \\
\hline 88.3 & 1720 & 139 & 635.3 & 36.93 \\
\hline
\end{tabular}

B. Cracking Load Calculation

The load size should be controlled, and the beam bending failure or shear failure should be avoided, when beam is put the third points loading. The preliminary design in the third points loading is $0.49 \mathrm{kN}$. The bending moment of beam span is:

$$
M(x)=R_{A} x-0.5 q x^{2}+F x-F(x-l / 3)
$$

$M$ reached maximum value is required:

$$
\frac{d M(x)}{d x}=0
$$

Equations (5) available: $x=l / 2$ and $M_{\max }=0.587 \mathrm{kN} . \mathrm{m}$ Maximum normal stress of the beam section is:

$$
\sigma_{\max }=\frac{M_{\max }}{I_{0}} y_{\max }
$$

The I0 above is cross section moment of inertia of the beam. ymax is the distance of section centroid to the edge.

The parameters were put into the formula to calculate, and the result is:

$$
\sigma_{\max }=1.73 \mathrm{~N} / \mathrm{mm}^{2}
$$

The tensile strength of $\mathrm{C} 40$ concrete material stated value is $f_{t k}=2.39 \mathrm{~N} / \mathrm{m}^{2}$, so the PC beam won't appear cracks.

\section{Beam End Partial Pressure Calculation}

Local compression bearing capacity of PC beam which place the grid type or indirect spiral reinforcement shall meet the following requirements:

$$
F_{l} \leq 0.9\left(\beta_{c} \beta_{l} f_{c}+2 \alpha \rho_{v} \beta_{c o r} f_{y v}\right) A_{l n}
$$

The area of the steel plate under the anchorage is $110 \mathrm{~mm} \times 110 \mathrm{~mm}$, so:

$$
A_{l n}=110 \times 110-\left(15.2^{2} \times \pi\right) / 4=11918.6 \mathrm{~mm}^{2}
$$

Put $\beta_{c}=1.0, \beta_{l}=1.0$, and $f_{c}=19.1 \mathrm{~N} / \mathrm{mm}^{2}$ into equation (4):

$$
F_{l}=90 \mathrm{kN}<0.9\left(\beta_{c} \beta_{l} f_{c}+2 \alpha \rho_{v} \beta_{c o r} f_{y v}\right) A_{l n}=204.87 \mathrm{kN}
$$

The results meet the provisions of the code for concrete structure design.

\section{TEST RESULT}

\section{A. Determination of Strength}

Leave a set of $150 \mathrm{~mm}$ cube test blocks when pouring the model beam, and conduct a compressive strength test of concrete after standard curing for 28 days. Then use the cube test blocks to conduct an elastic modulus test with a set of $150 \mathrm{~mm} \times 150 \mathrm{~mm} \times 300 \mathrm{~mm}$ prism test block.

Evaluate the strength of concrete with the methods that are stipulated according to Standard for Inspection and

\begin{tabular}{|c|c|c|c|c|c|}
\hline $\begin{array}{l}\text { Block } \\
1 \\
\text { /MPa }\end{array}$ & $\begin{array}{l}\text { Block } \\
2 \\
\text { /MPa }\end{array}$ & $\begin{array}{l}\text { Block } \\
\mathbf{3} \\
\text { /MPa }\end{array}$ & $\begin{array}{l}\text { Average } \\
\text { value of } \\
\text { strength } \\
/ \mathrm{MPa}\end{array}$ & $\begin{array}{l}\text { Standard } \\
\text { deviation } \\
/ \mathrm{MPa}\end{array}$ & $\begin{array}{l}\text { Intensity } \\
\text { value fcu,k } \\
\text { /MPa }\end{array}$ \\
\hline 41.1 & 41.1 & 45.7 & 42.6 & 2.17 & 40.9 \\
\hline
\end{tabular}
Evaluation of Concrete Strength: The arithmetic mean value of the compressive strength of the three specimens is used as the compressive strength value of the specimen, which is accurate to $0.1 \mathrm{MPa}$. As is shown in Tab. 2 .

TABLE II. THE MEASURED VALUE OF STRENGTH OF CONCRETE TEST BLOCK

B. Determination of Stress-strain Relationship of Concrete

The ratio of stress to strain of concrete is not a constant value. The stress-strain relationship of concrete prism is shown in Fig. 2 (the maximum value of concrete prism loading is about $50 \%$ of its compressive strength limit).As can be seen from Fig. 1, the stress-strain curves of concrete under single loading is approximately a straight line, $\bar{\sigma} / \bar{\varepsilon}=2.5388 \times 104 \mathrm{~N} / \mathrm{mm} 2$.

\section{Prestressed Concrete Deflection Test}

Exert load at third point of the test beam, and the peak load which is confirmed through preliminary determination is $50 \mathrm{~kg}$. After checking the load, it is obvious that there will be no load crack in the beam. Exert prestressing force to PC 
beam according to their levels, at the same time put load on third point of the beam, then collect the mid span deflection after holding load for 5 minutes. The measured value of deflection is shown in Tab. 3 .

TABLE III. EFLECTION VALUE OF PRESTRESSED BEAM

\begin{tabular}{|c|c|c|c|c|c|c|}
\hline \multirow{2}{*}{$\begin{array}{c}\text { Stretch } \\
\text { force/kN }\end{array}$} & \multicolumn{6}{|c|}{ Load in a third place/kg } \\
\cline { 2 - 7 } & 0 & 10 & 20 & 30 & 40 & 50 \\
\hline 0 & 0 & 0.099 & 0.188 & 0.253 & 0.353 & 0.461 \\
\hline 16.7 & 0 & 0.085 & 0.165 & 0.217 & 0.301 & 0.428 \\
\hline 34.9 & 0 & 0.081 & 0.146 & 0.203 & 0.283 & 0.401 \\
\hline 52.5 & 0 & 0.080 & 0.130 & 0.198 & 0.278 & 0.354 \\
\hline 69 & 0 & 0.071 & 0.127 & 0.183 & 0.265 & 0.348 \\
\hline 88.3 & 0 & 0.060 & 0.121 & 0.178 & 0.240 & 0.342 \\
\hline
\end{tabular}

\section{TheORETICAL ANALYSIS}

\section{A. Calculation Formula of the Code}

The short-term stiffness of PC beam was calculated according to Code for Design of Concrete Structures (GB50010-2010). The expression can be shown in the following:

$$
B_{0}=0.85 E_{C} I_{0}=4.804 \times 10^{11} \text { N.mm }{ }^{2}
$$

The short-term stiffness of PC beam was calculated according to the Code of Concrete Highway Reinforced Concrete and Concrete Bridge Design(JTGD62-2004):

$$
B_{0}=0.95 E_{C} I_{0}=5.369 \times 10^{11} \mathrm{~N} . \mathrm{mm}^{2}
$$

Calculate the mid span deflection by the material mechanics formula, then exert two concentrated forces to the third point of the beam. The mid span deflection value is:

$$
f=\left(2 F l / 144 B_{0}\right)\left(3 l^{2}-4 l^{2} / 9\right)
$$

The calculated deflection values are shown in Tab. 4 .

TABLE IV. DEFLECTION CALCULATION OF PC BEAM

\begin{tabular}{|l|c|c|c|c|c|}
\hline Load of the third point $\mathbf{P}(\mathbf{N})$ & 98 & 196 & 294 & 392 & 490 \\
\hline Code $1 \mathbf{f}(\mathbf{m m})$ & 0.077 & 0.154 & 0.231 & 0.308 & 0.386 \\
\hline Code $2 \mathbf{f}(\mathbf{m m})$ & 0.069 & 0.138 & 0.207 & 0.276 & 0.345 \\
\hline
\end{tabular}

\section{B. Comparison of Experimental Results and Calculation Value}

Take the deflection of the prestressed beam with tension force of $88.3 \mathrm{kN}$ as an example, when the load is $392 \mathrm{~N}$ at third point ,compared with the calculated values of the two codes, the error between the deflection value calculated by the stiffness of the Code for Design of Concrete Structure
(GB50010-2010) and the deflection value from the test is $28.33 \%$. And the error between the deflection value calculated by the stipulation of Specification for Design of Highway Reinforced Concrete and Prestressed Concrete and the deflection value from the test is $15 \%$. As is shown in Figure III, the deflection value that is calculated by the standard is close to the deflection value without prestressing force. Under the larger prestressing force, the error of the deflection of beam that is calculated by the short- -term stiffness with the specification is much larger.

\section{CONCLUSIONS AND RECOMMENDATIONS}

It can be seen from the experimental results that prestress has a significant impact on the short-term stiffness of the full- prestressed beam. The greater the prestress is, the greater the stiffness of the beam will be, and under the same load, the deflection of the beam will be smaller. And yet the existing literature or the specification does not consider the effect of prestress on the short-term stiffness of the beam. Therefore, the authors suggest that the influence of prestress on the stiffness should be considered in the design of the component with more precision. In addition, according to the results of the test it can be seen that there is a close relationship between the deflection increment of the full-prestressed beam and the prestressing force, thus the increment of deflection can be utilized to predict the loss of prestressing force.

\section{REFERENCES}

[1] Code for Design of Concrete Structures (GB50010-2010), Industry standard of the People's Republic of China, Beijing: Building industry, 2011.

[2] Code for Design of Highway Reinforced Concrete and Prestressed Concrete (JTGD62-2004) [S] , Industry standard of the People's Republic of China, Beijing: Building industry, 2004.

[3] Jeong-Tae Kim,Yeon-Sun Ryu, chang-Bang Yun, "Vibration-based method to detect prestess-loss in beam-type bridges," Proceedings of SPIE, Vol.5057, pp.559-567, April 2003.

[4] Saiidi M., Douglas B., Feng S, "Prestress force effect on vibration frequency of concrete bridges," Journal of structural Engineering, Vol.120(7), pp.2233-2241, May 1994.

[5] Arek Higgs, S.M, Paul J. Barr, M. and Marvin W. Halling, F. Comparison of Measured and AASHTO LRFD-Predicted Residual Prestress Forces, Shear and Flexural Capacities of High-Strength Prestressed-Concrete Bridge Girders[J], Journal of Bridge Engineering, Vol. 20(1), pp.94-102, January 2015.

[6] [6] Yazhou Xie and Jian Zhang, "Optimal Design of Seismic Protective Devices for Highway Bridges Using Performance-Based Methodology and Multiobjective Genetic Optimization," Journal of Bridge Engineering, Vol. 116, pp.628-635, November 2016.

[7] Zeng. D, Wang, G., Xie, J., and Zheng, X, "Exploratory Experimental Study on Fatigue Prestress Loss of Prestressed Concrete Beams," Journal of Highway and Transportation Research and Development (English Edition), Vol. 118, pp.268-233, May 2014.

[8] Yilan Zhang, Masahiro Kurata, and Jerome P. Lynch, "Long-Term Modal Analysis of Wireless Structural Monitoring Data from a Suspension Bridge under Varying Environmental and Operational Conditions: System Design and Automated Modal Analysis," Journal of Engineering Mechanics, Vol. 257, pp.1189-1195, November 2016.

[9] Shane D. Boone, Paul J. Barr, and Marv W. Halling, "A Comparison of Prestress Losses in a Prestressed Concrete Bridge Made with High Performance, Self Consolidating Concrete," New Horizons and Better Practices, Vol. 30(5), pp.3277-3285, May 2010. 

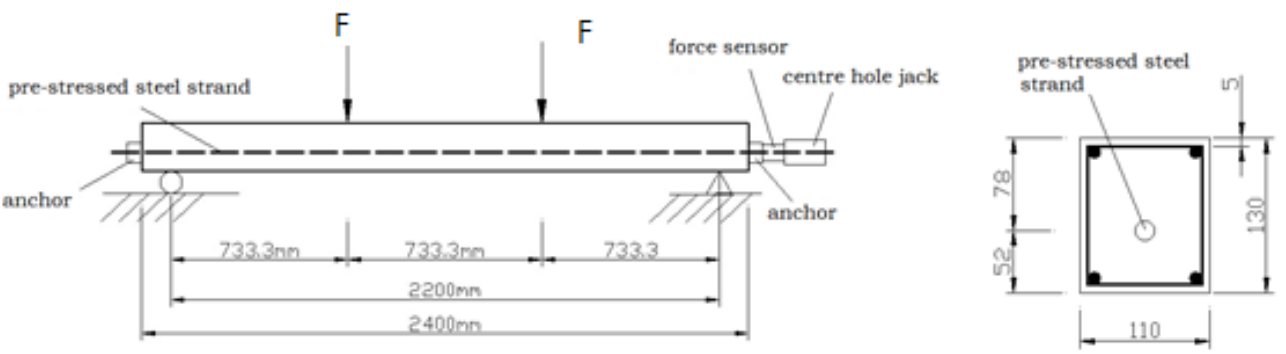

Figure 1. Schematic diagram of test beam

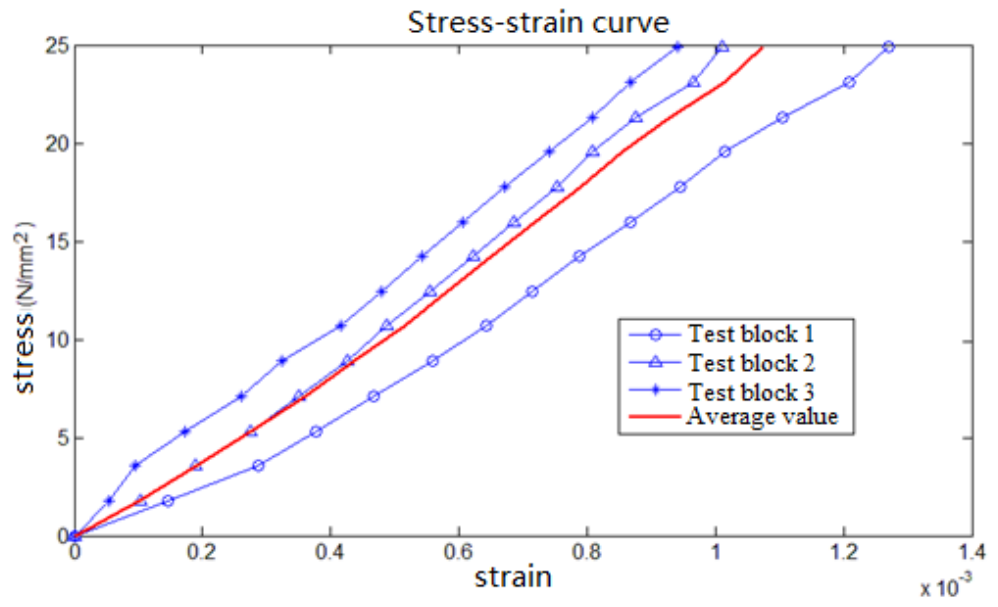

Figure 2. Stress strain curve of concrete test block

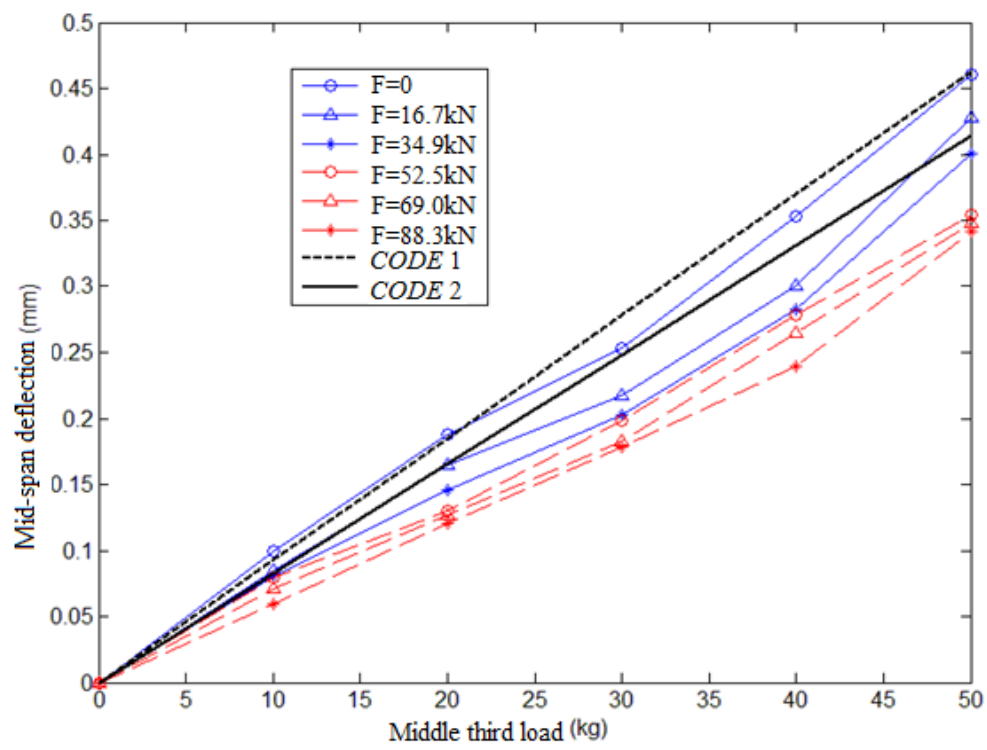

Figure 3. Comparison between experimental results and calculated results

Note: $\mathrm{F}$ is the stretching force on the PC beam.

CODE 1 is Code for Design of Concrete Structures (GB50010-2010).

CODE 2 is Code for Design of Highway Reinforced Concrete and Prestressed Concrete (JTGD62-2004). 